\title{
Memória, trabalho e identidade: trajetórias de vida de mulheres idosas dos quilombos Botafogo e Caveira na Região dos Lagos (RJ)
}

\author{
Dayara da Silva Ferreira* \\ ORCID iD 0000-0003-0248-5956 \\ Universidade Federal do Rio de Janeiro, Programa de Pós-Graduação em Serviço Social, Rio de Janeiro, Brasil
}

\begin{abstract}
Resumo: $\mathrm{O}$ artigo é resultado da pesquisa de dissertação de mestrado, cuja análise versou sobre as trajetórias de vida de mulheres idosas dos quilombos Botafogo e Caveira, ambos situados na Região dos Lagos (RJ). Recuperei a memória das idosas através do método de História de Vida, a partir de um lapso temporal que compreende o período da infância à velhice. Destacam-se as temáticas mais recorrentes em suas narrativas, que são: trabalho, identidade, solidariedade e religiosidade. Exponho tais conceitos à luz de autores clássicos, como Halbwachs, Pollak, Lins de Barros e Bosi. Explicito ainda como se dão as relaçóes sociais estabelecidas em ambos os quilombos, bem como as experiências compartilhadas nos eventos cotidianos, principalmente na prática do plantio, tida como atividade de maior importância. Recupero a vivência das idosas mediante as práticas de cuidado, solidariedade e participação social na vida religiosa, que se constituem como redes de apoio social.
\end{abstract}

Palavras-chave: Trajetórias de vida. Memória. Trabalho. Identidade. Solidariedade. Religiosidade. Serviço Social.

\section{Memory, labour and identity: life trajectories of elderly women from the Botafogo and Caveira quilombos in the Region of Lagos (RJ)}

Abstract: The article is the result of a master's dissertation research, whose analysis dealt with the life trajectories of elderly women from Quilombos Botafogo and Caveira, both located in the Region of Lagos (RJ). I recovered the elderly's women memorys through the Life History method, from a time lapse that includes the period from childhood to old age. The most recurring themes in their narratives stand out, which are: work, identity, solidarity and religiosity. I expose such concepts in the light of

Mestre em Serviço Social pela Universidade Federal do Rio de Janeiro (UFRJ), com orientação da Profa. Dra. Myriam Moraes Lins de Barros. E-mail: dayara.ferreira@hotmail.com. 
classic authors, such as Halbwachs, Pollak, Lins de Barros and Bosi. Explicit is still the social relations between both quilombos, as well as the experiences shared in everyday events, mainly in the practice of planting, considered as a most important activity. I recover the experience of the elderly women through the practices of care, solidarity and social participation in religious life, which constitute networks of social support.

Keywords: Life trajectories. Memory. Work. Identity. Solidarity. Religiosity. Social Work.

\section{Introdução}

A pesquisa teve como principal objetivo analisar as trajetórias de vida de sete mulheres idosas das comunidades quilombolas Botafogo ${ }^{1}$ e Caveira ${ }^{2}$, ambas situadas na Região dos Lagos (RJ), bem como compreender sua participação social nos locais, ou seja, entender qual o papel que exercem nos referidos quilombos.

As análises foram construídas a partir da recuperação e valorização de suas memórias, com base no que Halbwachs (1990) denomina de "quadros sociais da memória". Assim, as narrativas foram sendo construídas mediante a rememoração desses quadros, considerados etapas da vida, como: a infância, a adolescência, a juventude e a velhice.

O estudo se insere em quatro áreas: memória, trabalho, identidade e religiosidade, perpassando por outras temáticas como envelhecimento, família, participação social, gênero e geração. Esta pesquisa pretendeu ainda dar visibilidade à participação social das mulheres idosas nas comunidades mencionadas.

A discussão se inicia com a apresentação dos sujeitos da pesquisa. Posteriormente, o debate recai acerca da memória, a partir das contribuiçôes de Halbwachs, Pollak, Lins de Barros e Bosi. A seguir, recupero a trajetória e a memória do trabalho na roça. Discorro ainda sobre memória e identidade, trazendo alguns apontamentos de Pollak.

Analiso as redes de solidariedade e reciprocidade familiar como redes de apoio

1 O Quilombo Botafogo está localizado há $40 \mathrm{~km}$ do centro da cidade de Cabo Frio e aproximadamente a $150 \mathrm{~km}$ da capital do Rio de Janeiro. Atualmente, vivem no território mais de 100 famílias. O Quilombo Botafogo foi constituído por pessoas que descendem dos escravos da antiga Fazenda Campos Novos. Tal fazenda, na época funcionava como centro de distribuição de escravizados africanos que vinham em navios e eram desembarcados em Búzios. (Costa, 2016).

2 A Comunidade Remanescente de Quilombo Caveira se caracteriza como um espaço identitário de um território de descendentes africanos. Está localizada na área rural do município de São Pedro da Aldeia, que fica a $135 \mathrm{~km}$ da cidade do Rio de Janeiro. Hoje comporta aproximadamente cerca de 280 famílias, o que significa, em números, cerca de 1.200 pessoas, que vivem numa área com cerca de 220 hectares. A área foi ocupada por descendentes de escravos antes mesmo da abolição da escravatura, os quais foram destinados ao trabalho na lavoura e na criação de pequenos animais (Costa, 2016). 
e ajuda mútua. Estas se tornam uma espécie de proteção social aos membros da comunidade, na medida em que têm suas necessidades sociais atendidas.

Por meio da solidariedade das famílias nas duas comunidades, percebe-se que os sujeitos que ali estáo têm suas necessidades sociais mais básicas atendidas, pois, a partir da organização coletiva, eles unem forças para lidar com as questóes extremas advindas da situação de pobreza, à qual as pessoas negras estão submetidas.

Recupero ainda os aspectos da religiáo e religiosidade, bem como as trajetórias religiosas das idosas. A partir das proposiçóes, podemos perceber que além da questão da conversão, fator que merece destaque na narrativa das idosas, o papel da religiosidade na fase da velhice contribui de forma significativa para a qualidade de vida das mulheres idosas, uma vez que é nessa etapa da vida que muitas delas vêm conseguindo realizar novos projetos de vida, devido à chegada da aposentadoria, quando o tempo parece se alargar.

Considerando que mulheres negras e pobres historicamente têm suas histórias de vida apagadas ou contadas por terceiros, essa pesquisa se torna relevante na medida em que contribui para trazer visibilidade social a essas mulheres, por meio da valorizaçáo de suas memórias. A ideia, portanto, foi trazer as vozes das idosas, a fim de apresentá-las como protagonistas da sua própria história.

Em suma, esta pesquisa se torna importante para o campo do conhecimento científico na medida em que recupera através das mulheres idosas, consideradas como guardiās da memória, as vivências e experiências do meio rural, e coloca em xeque as desigualdades e violaçóes a que as mulheres quilombolas estão submetidas, devido à quádrupla condição de vulnerabilidade, que engloba os aspectos de geração, gênero, raça e classe.

\section{Identificação das narradoras da pesquisa ${ }^{3}$}

Dandara dos Palmares - Natural do município de Cabo Frio (RJ), 62 anos de idade, aposentada, viúva, mora sozinha, estudou até a admissão, sua renda é de dois saláriosmínimos, mãe de três filhos, teve sete netos, agora seis, e dois bisnetos. Não tem religião. Reside no Quilombo Botafogo.

Considerando que a pesquisa teve como enfoque trazer as vozes das mulheres idosas dos quilombos supracitados, a fim de apresentá-las como protagonistas da sua própria história, parece um tanto contraditório utilizar pseudônimos para representá-las. Portanto, é válido ressaltar que tal escolha se deve ao seguinte fato: as mulheres negras que fizeram história no país, ao longo do tempo, tiveram suas trajetórias e histórias de luta apagadas, interrompidas ou contadas por terceiros, geralmente por pessoas não negras, ou seja, mulheres que foram invisibilizadas, exatamente porque temos sido faladas infans, como nos aponta Lélia Gonzalez (1984). A escolha das personagens históricas aqui trazidas 
Tereza de Benguela - Natural do município de São Pedro da Aldeia (RJ), 64 anos de idade, aposentada, casada. Mora com o esposo, estudou até a admissão, sua renda é de dois salários-mínimos, mãe de três filhos, tem cinco netos. É evangélica. Residiu no Quilombo Botafogo.

Tia Ciata - Natural do $3^{\circ}$ distrito do município de Cabo Frio (atualmente Armaçáo dos Búzios), têm 80 anos, aposentada, viúva há dezenove anos, mora sozinha, estudou até a segunda série, sua renda é de dois salários-mínimos, mãe de três filhos, agora dois, tem quatro netos. É evangélica. Reside no Quilombo Botafogo.

Marielle Franco - Natural do $3^{\circ}$ distrito do município de Cabo Frio (atualmente Armação dos Búzios), têm 70 anos, aposentada, viúva. Mora sozinha, estudou até a segunda série, é feirante, sua renda é de um salário-mínimo, mãe de quatro filhos, um é falecido, tem sete netos e dois bisnetos. É evangélica. Reside no Quilombo Caveira.

Aqualtune - Natural do município de São Pedro da Aldeia, 85 anos, aposentada, casada há 63 anos, mora com o esposo, é analfabeta funcional, sua renda é de um salário-mínimo, máe de treze filhos, três falecidos, tem mais ou menos 31 netos e mais ou menos 13 bisnetos. É evangélica. Reside atualmente no Quilombo Botafogo.

Luíza Mahin - Natural do município de Cabo Frio, 77 anos, aposentada, casada há 57 anos, mora com o esposo, estudou até a quarta série, sua renda é de um salário-mínimo, mãe de seis filhos, tem 17 netos e dois bisnetos. É evangélica. Reside atualmente no Quilombo Caveira.

Carolina de Jesus - É natural de São Pedro da Aldeia, têm 62 anos, aposentadoria em processamento, viúva há três anos, mora sozinha, estudou até a quarta série, não especificou a renda, mãe de dois filhos, tem uma neta. É evangélica. Reside atualmente no Quilombo Caveira.

pretende mostrar o quão semelhante é a história de vida delas com a das mulheres da pesquisa, pretende demonstrar ainda, que antes delas vieram outras mulheres, as quais não são trazidas nos livros de história. Falar dessas figuras históricas é reconhecer também as resistências e as lutas das mulheres negras idosas quilombolas, que apesar de terem tido importância social nas comunidades em que vivem/ viveram, assim como as figuras históricas aqui citadas, pelos seus feitos no âmbito da arte, da cultura e da história, não foram/são reconhecidas devido principalmente às estruturas de opressão patriarcal e racista presentes na sociedade capitalista. Com isso trarei as vozes das mulheres idosas quilombolas, que falam por si, de si e por outras. As verdadeiras identidades podem ser conferidas na lista de fontes orais ao final do trabalho. 


\section{A memória à luz de Maurice Halbwachs, Myriam Lins de Barros, Michael Pollak e Ecléa Bosi}

Através da rememoração que essas mulheres constroem suas narrativas, destacando os acontecimentos relevantes que marcaram suas trajetórias de vida ao longo do tempo. Nesse processo, é importante destacar que a memória familiar se constituiu enquanto elemento fundamental para a reconstituiçáo do passado. Lins de Barros (1989) aponta o grupo familiar como elemento fundamental para resgatar a memória do passado, através da família as recordaçôes se avivam, as trajetórias e relaçóes internas são reconstruídas pelas idosas.

Para Halbwachs (1990) a memória é um fenômeno social. Ela não é exclusivamente individual, pelo contrário, se constrói coletivamente de modo diversificado. A memória para o autor envolve o tempo-espaço, é a junçâo das lembranças de um tempo longínquo com as vivências do presente. É esse complemento do passado com o presente que permite a produção da memória.

$\mathrm{O}$ autor aponta que as referências reconstruídas através da memória devem partir do que ele denomina de "quadros sociais", pois estes quando não levados em consideração como ponto de partida para recuperaçáo da memória, esta se torna impossível de vir à tona. Mas o que seriam esses "quadros sociais da memória?” Halbwachs (1990, p. 9-10) os conceitua como memórias que estão sujeitas aos suportes sociais, ou seja, ele associa quadros sociais aos "campos de significados que nos servem como referência".

Halbwachs (1990) defende "o caráter eminentemente social da memória", afirma que a mesma está embutida numa relação social que envolve indivíduo e sociedade. O indivíduo recorda a partir de dado período que considera marcante pra si, isto é, parte de uma referência (dos quadros sociais), bem como elenca os atores partícipes da mesma vivência, os quais também julgam como essenciais para reconstruçấo dessa memória.

A memória do trabalho se caracteriza como individual, pois se atrela às experiências e vivências daquele sujeito que é único, porém contém aspectos da memória de um grupo, que neste caso são as idosas. Afirmamos isso, pois ao analisarmos suas narrativas, percebemos que a memória acerca do trabalho foi um ponto em comum entre elas, todas rememoraram a trajetória do trabalho na lavoura como um período marcante em suas vidas, remontando a um passado que é extensivo ao presente.

Sobre isso, Lins de Barros (1989, p. 34) afirma que "o presente está constantemente referido a um passado, náo um passado relatado linearmente, mas pinçado aos poucos num processo de associaçôes entre hoje e ontem, seja este ontem distante ou não". Para Halbwachs, a memória coletiva também classifica. $\mathrm{O}$ autor afirma que:

[...] "o indivíduo, ao se comportar como membro de um grupo, contribui para evocar as lembranças que o grupo conseguiu selecionar. Nesse sentido, a memória é 
seletiva e diz respeito à vida de cada grupo em particular. É no conceito de memória coletiva que se encontra a história vivida". (Halbwachs, 1968, apud Lins de Barros, 1989, p. 32).

Sobre os dois tipos de memória, Halbwachs aponta que "a memória coletiva, envolve as memórias individuais, portanto não se confunde com elas" (Halbwachs, 1990, p. 53). Segundo Bobbio (1997, p. 30), "somos aquilo que lembramos". A partir da noçáo exposta pelo autor percebemos que através da memória também construímos nossa identidade, ou seja, ambas as categorias estão imbricadas e o fato de recordar permite a cada sujeito criar a sua própria história.

As idosas deste estudo estáo inseridas numa rede comunitária em que a noção de pertencimento é reavivada de modo muito significativo. Nessa relaçáo social é que se constrói a memória, como nos aponta Halbwachs (1990).

A memória coletiva está baseada nas recordaçôes que, ao serem ressignificadas pelas idosas entrevistadas, se assemelham, pois pertencem a um mesmo grupo. Assim, sáo relembrados por elas os quadros sociais da infância, da adolescência, do casamento, do trabalho na lavoura, das festas na comunidade, das práticas de solidariedade, etc. "As memórias coletivas passam a ser sinônimos de representaçóes coletivas que trazem com elas uma dimensáo histórica" (Santos, 2012, p. 17).

A memória vai além das vivências e experiências experimentadas pelos sujeitos, ela resulta de um determinado contexto social, está situada no íntimo de cada pessoa. Às vezes náo lembramos de imediato o que gostaríamos de lembrar, mas quando somos instigados a recuperar a memória, quando participamos de alguma pesquisa, por exemplo, vemos que a lembrança está ali, no nosso âmago. Barros e Lins de Barros (2014) afirmam que, para Halbwachs, "estas recordaçóes estáo alojadas no inconsciente, mas acionadas pela força da interaçáo em que cada um sabe como trabalhar a memória, pois as marcas do caminho já estáo presentes nos indivíduos (Lins de Barros, 1987, p. 76)”.

Para Michael Pollak (1989, p. 10), "quando vemos os pontos de referência de uma época longínqua, frequentemente os integramos em nossos próprios sentimentos de filiação e de origem". O autor fala de uma memória oficial em contraposição a uma memória subterrânea, sendo esta última relegada ao silêncio.

Pollak (1989) afirma que a memória dos grupos minoritários sofre o processo de silenciamento. Esta pesquisa veio na contramão desse silenciamento às mulheres idosas quilombolas, por isso tendi desde o início da pesquisa a resgatar a memória oficial dessas mulheres através da história oral ${ }^{4}$ a fim de evidenciar o protagonismo merecido.

4 "'História oral' é um termo amplo que recobre uma quantidade de relatos a respeito de fatos não registrados por outro tipo de documentação, ou cuja documentação se quer completar. Colhida por meio de entrevistas de variadas formas, ela registra a experiência de um só indivíduo ou de diversos indivíduos de uma mesma coletividade. Neste último caso, busca-se uma convergência de relatos sobre um acontecimento ou sobre um período do tempo" (Queiroz, 1987, p. 6, apud Lima, 2016, p. 30). 
Ter suas histórias contadas por terceiros é uma forma de apagá-las, mas também é uma forma de silenciá-las.

Para Halbwachs (2004, p. 8) "es en la sociedad donde normalmente el hombre adquiere sus recuerdos, es alli donde los evoca, los reconoce y los localiza". Essa concepção reforça a análise feita pelo autor de que a memória só se produz pela via dos quadros sociais. Sendo assim, neste estudo identificou-se a reconstrução da memória das idosas em distintos períodos de suas vidas, bem como dos indivíduos que os circundam, isto é, aqueles com os quais estabelecem algum tipo de relação social.

\section{Memória do trabalho}

A memória do trabalho se apresenta como a mais significativa pelas idosas. Neste tópico proponho apresentar a memória das práticas tradicionais do trabalho familiar no campo perpetuado no dia a dia das mulheres idosas, uma categoria que caracteriza o modus vivendi quilombola e que marca bastante a trajetória de vida delas, principalmente em relaçáo ao aprendizado do trabalho, o qual foi ensinado por seus antepassados. É a partir da rememoração da vida laborativa que as idosas estruturam suas memórias, criando unissonância entre modo de vida e trabalho. Isto é, significa que o segundo é parte do primeiro.

É através do trabalho que o indivíduo realiza o intercâmbio com a natureza e é compreendido social e coletivamente. Corroboro tal afirmativa relacionando a cooperação da família no trabalho na lavoura, onde cada membro desta estabelece uma relação dialética com a terra.

Para Tia Ciata, o trabalho lhe ensinou muito. A idosa guarda na memória o aprendizado dessa atividade e assim relata:

Ah, plantava milho, plantava rama, plantava cana, plantava... tudo isso, a gente plantava, plantava fruta, que eu ainda tenho meus pezinho de abacate, tenho, acerola, só que agora tá tudo puro, num tem nada... Tudo isso tem, tudo isso eu plantava... foi plantado com as... com as mãos da gen... com as 'nossas mão'. (Tia Ciata, 2019).

É notável perceber através do relato da idosa que o aprendizado das mulheres com o trabalho é algo que elas foram aperfeiçoando ao longo do tempo, o próprio ato de produzir e a repetiçấo das tarefas na lavoura contribuindo para tal aperfeiçoamento. A prática do trabalho como costume do cotidiano fez com que essas mulheres o considerassem como parte de si mesmas, ou seja, o trabalho causou impacto nas subjetividades das idosas, bem como em suas relaçóes familiares e sociais de modo geral. Sobre a memória do trabalho no período da infância, as idosas trazem as seguintes narrativas: 
[...] fazia era cuidar de cavalo, trabalhar de enxada, de foice, machado, enxadão, fazer comida pra porco, pra cavalo... ah, minha filha, isso era uns oito 'ano', daí tô trabalhando até hoje, que 'intigamente' num tinha esse negócio, que filho num 'pudia' trabalhar porque era de menor, não, tinha que trabalhar, plantava feijão, era milho, cana, moía cana pra fazer café, que num tinha açúcar pra fazer café, no suvaco, você num sabe nem o que que isso... [gargalhada]. (Marielle Franco, 2019).

As idosas relatam que conciliavam o estudo, o trabalho na roça e o trabalho doméstico. Dona Aqualtune (2019) diz: "eu trabalhava muita lenha, quando era nova, eu trabalhava numa enxada, assim pra ajudar meus pais, né. Meu pai ficou doente dez "ano". O trabalho desde sempre tem um significado valoroso para essas idosas, pois representa a prática do saber.

Segundo Tiriba (2008, apud Rocha, 2015, p. 73), através da prática do trabalho, os indivíduos produzem saber e o amplia para as demais instâncias das relaçóes sociais estabelecidas nas comunidades. Tal prática é representada pelo legado entre as geraçóes.

O trabalho exercido pelas mulheres, como aponta Dona Aqualtune, é caracterizado como ajuda. Perrot (2007) aponta que historicamente as mulheres sempre estiveram envolvidas com o trabalho, porém suas atividades não são caracterizadas como tal, pelo fato de exercerem na maior parte das vezes funçóes tidas como desqualificadas, geralmente em espaços privados, as quais não exigem intelectualidade. Assim, suas atividades, além de serem desvalorizadas, são reconhecidas como "ajuda", logo, não há remuneração.

No imaginário social da sociedade em geral, as mulheres sáo criadas para exercerem a função da maternidade, bem como exercer o cuidado aos filhos, ao marido, aos doentes, às pessoas idosas, etc. São as chamadas qualidades "naturais e inatas" que se definem como "ofício de mulher" (Kergoat, 2011). A desvalorização do trabalho feminino é resultante, portanto, dessa construção social, marcada pelo gênero, onde a mulher é destinada para atuar no espaço privado, seja em casa, ou na roça, e os homens no espaço público.

A memória do trabalho para Carolina de Jesus (2019) deixou marcas inscritas em seu corpo. A idosa relembra: "Aqui planto minha filha... aqui [mostra a mão marcada], aqui ó... ó, tá vendo?... a mão de calo, né. Tá até hoje minha filha... eu planto... marcada, marcada. Faço minha plantação, vivo da minha plantação entendeu”. Esse corpo traz as marcas mais visíveis e aparentes de suas velhices, um corpo desgastado pelo trabalho maçante no campo. Essas marcas são características dos trabalhadores e trabalhadoras rurais.

Tereza de Benguela relata as marcas presente em seu corpo, as quais são resultantes do trabalho duro na roça. A idosa diz:

[...] eu tenho esse dedo cortado, hoje marcado por... de serrar mandioca, raspava 
muita mandioca, plantava muita rama, muito milho... e a gente levantava cedo... assim cinco 'hora' da manhã papai já chamava a gente pra ir pra roça. (Tereza de Benguela, 2019).

As idosas relataram que a questão do trabalho familiar no campo é algo que remete mais ao passado, ou seja, não tem mais a força dos tempos antigos. Algumas idosas seguem na plantação atualmente, porém de modo muito sutil, se comparado ao passado, o que tem relaçáo também com o desgaste do corpo físico, ou seja, resultado do processo de envelhecimento ao qual elas vêm experimentando. E a prática do trabalho na lavoura também não tem gerado interesse na juventude atual, portanto é uma tradição que vem sendo rompida.

\section{Memória e identidade}

Abordar ambos os conceitos, memória e identidade, nos faz pensar em duas perguntas: que lembranças e/ou recordaçóes eu tenho sobre o que vivi? E mais: quem sou eu? Tais indagaçóes são analisadas por Brandão e Mercadante (2009), que afirmam:

[...] somos memória porque a identidade - Quem sou? - está vinculada às lembranças que cada um tem de si - seu nome, os dos seus ancestrais, do lugar de nascimento e outros espaços - territoriais e sociais - que ocupamos ao longo da vida - dimensão pessoal, que envolve fatos objetivos e subjetivos. (Brandão; Mercadante, 2009, p. 75).

A questão colocada pelas idosas no que concerne à identidade é percebida quando elas iniciam suas narrativas falando exatamente sobre quem elas são, de onde vieram, quem são seus ancestrais, onde e como nasceram, quais são seus hábitos e costumes, as relaçóes sociais estabelecidas, etc.

Segundo Boni (2005, apud Lusa, 2012, p. 98), "a construção da identidade da mulher no campo teve e persiste sendo fortemente impregnada pelo patriarcado, qualificando o lugar social e político de mulheres e homens nas relaçốes de produção e nas relaçôes sociais do núcleo familiar rural".

Ciampa (2003, p. 186) explicita que, ao passo que as transformaçóes na identidade vão ocorrendo, simultaneamente ocorrem mudanças na consciência dos sujeitos, que "estão entrelaçadas e acontecem no cotidiano a partir das trajetórias de vida das pessoas".

Trajetórias de vida ou trajetórias identitárias são entendidas como o processo de apreensão da realidade, aprendizagem da qual cada indivíduo, mergulhado numa cultura social ampla e familiar, abstrai, a partir de sua percepçáo única, reordena e 
transforma num projeto, profissão, modo e estilo de vida. (Brandão; Mercadante, 2009, p. 63).

A identidade dos sujeitos sociais vai depender diretamente da memória que cada um constrói ao longo da vida. Esse tempo de construçáo é onde se apreende o real, ou seja, período que abrange o intervalo vida e morte, é o que os autores chamam de trajetória de vida, onde a forma de interaçáo com o mundo é o ponto chave para a construçáo da identidade. E para construção e reconstrução dessa identidade, a memória se torna determinante.

O termo identidade é dotado de inúmeros significados. A interação estabelecida pelos indivíduos no meio social também contribui para a constituição desta. As mulheres idosas constroem suas identidades a partir dessas interaçóes, as quais provocam mudanças significativas em si, ou seja, em suas subjetividades. Ao se transformarem através desses processos sociais experimentados, elas formam as suas visóes de mundo, bem como formam e constituem suas identidades.

Ser mulher e ser pertencente ao meio rural é uma importante fonte de significado da identidade. Em relação a essa identidade cultural, as idosas trazem na memória os tempos de resistência, as diversas tentativas de expulsão de suas terras. Toda essa resistência e as lutas travadas se apresentam como marcas da memória que caracteriza a identidade de um grupo social, que nesta pesquisa são mulheres idosas quilombolas.

Através dos depoimentos das entrevistadas, é perceptível a identidade atribuída ao envelhecimento, quando relatam, por exemplo, os corpos já cansados do trabalho na lavoura. A percepçáo acerca da experiência com o envelhecimento diz respeito basicamente ao uso do corpo, ou seja, destaca-se o aspecto físico, as alteraçóes corporais, fazendo com que elas se identifiquem como pessoas idosas (embora isso não seja um impedimento para que prossigam trabalhando). Há apenas uma moderação da atividade, segundo apontam, pois "as forças vão acabando".

A questấo de se identificarem enquanto idosas surge ainda quando elas depóem acerca dos projetos de vida nessa fase em que experimentam a velhice (relacionada à aposentadoria), projetos esses que já estâo sendo executados, como, por exemplo, a participação ativa na igreja, onde elas e demais mulheres idosas têm a possibilidade de reunirem-se em grupos, fazerem viagens, conhecer outras igrejas e demais locais, onde podem exercer a sociabilidade e realizar trocas intergeracionais, ao repassarem "ensinamentos aos jovens".

Tais eventos se caracterizam como atividades de lazer que, em dado momento da vida, as idosas não puderam exercer de modo tão intenso, devido principalmente à responsabilidade que lhes era atribuída desde a infância, que era o trabalho duro na lavoura. Elas dizem: "primeiro era a obrigação". Nesse sentido, essa nova etapa da vida é um momento de satisfação e realização pessoal para elas, onde as "obrigaçóes" do passado já não fazem mais parte do presente. 
Bosi (1994) afirma que é nesse momento da velhice que as pessoas exercem uma função própria, que é a de lembrar. A autora aponta que nós tendemos a estimar os mais velhos indagando-os com questóes do passado, pois sabemos o quanto carregam de lembranças valiosas, adquiridas com a experiência do tempo vivido. Essa recordação e/ou reconstrução do passado através da memória familiar, conforme aponta Lins de Barros (1989), é imprescindível para a construção das identidades das pessoas idosas.

\section{Redes de apoio, reciprocidade e solidariedade nos Quilombos Botafogo e Caveira}

A reflexão inicial se baseia em um questionamento apontado por Todorov (1995) para entender como se dáo as práticas de reciprocidade e solidariedade nas comunidades supracitadas. A questáo que se coloca se volta à seguinte indagaçáo: como as mulheres idosas agiam em face do extremo para garantir sua sobrevivência e da família, isto é, para garantir o bem-estar da coletividade? Nesta pesquisa, as idosas narram como as redes eram formadas por vínculos de solidariedade e afinidade, o que possibilitava o acesso a alguns serviços que acabavam por garantir a proteçáo social dos sujeitos sociais, ao atenderem as suas necessidades básicas, como alimentação e segurança. Tais serviços deveriam ser ofertados pelo poder público, porém é sabido que em territórios quilombolas, os quais são historicamente segregados, as políticas quase nunca chegam e quando se fazem presentes são extremamente fragmentadas. Nesse sentido, resta aos indivíduos organizarem-se coletivamente para garantir suas necessidades sociais e a dos membros da família.

Fonseca (2005, p. 52) corrobora com tal afirmativa, ao dizer que "as famílias negras pobres, que vivem em condiçôes de grande precariedade econômica, só conseguem sobreviver porque criam extensas redes de ajuda mútua”. Entretanto, acaba ficando a cargo exclusivo da família toda a responsabilidade na prestaçáo dos cuidados aos seus membros, sejam eles dos mais básicos aos mais complexos, o que Debert (1999), ao analisar o processo de envelhecimento, chama de reprivatizaçáo da velhice ou do cuidado, que nada mais é do que uma responsabilidade atribuída exclusivamente à família, ou seja, sem a interferência do Estado, quando na verdade deveria ser uma responsabilidade compartilhada.

A concretização dos programas e açóes voltadas aos quilombolas é fruto da organizaçáo coletiva da sociedade civil, isto é, do movimento negro, em especial. As pressóes travadas na década de 1990 pela população negra permitiram a materializaçáo dos direitos explicitados na constituição cidadã e, consequentemente, possibilitaram aos sujeitos avançarem em suas lutas na promoção da igualdade racial.

A reciprocidade ocorre a partir das relaçóes sociais estabelecidas, assim ela também é construída. É proveniente das relaçôes familiares, ou seja, de parentesco bem como da relação de vizinhança, onde as trocas são parte do cotidiano das pessoas. 
Trocas essas exercidas entre os membros de diversas geraçōes, crianças, mães, tias e avós, que se unem para partilhar os serviços e os cuidados domésticos, principalmente em relação às crianças.

Nas duas comunidades, a participação das mulheres se destaca de diversas formas. Em suas narrativas são expostas também as práticas de cuidado exercidas pelas parteiras. As idosas relacionam a atuaçáo dessas mulheres como uma prática de cuidado alternativo que caracteriza a solidariedade e a reciprocidade, a qual é proveniente do conhecimento tradicional próprio das comunidades rurais e passada de geraçáo a geração, por mães, tias, avós, etc. Conforme aponta Carolina de Jesus, tais práticas de cuidado ocorriam da seguinte forma:

Dava dor de ganhar o neném lá na roça, tinha que vim pra casa, chamava a falecida minha vovó... minha vó era parteira. E tinha tia... ah meu Deus, 'xô' lembrar agora, que é a bisavó de Conceição, de 'Ção', que é mãe Alta. Todo mundo chamava de mãe. Era 'as parteira' que tinha aqui. (Carolina de Jesus, 2019).

As práticas de partejar, que representavam o cuidado cultural nos quilombos, era uma "tradiçáo local", que perpassava por diversas geraçóes, não ocorria simplesmente devido à ausência de serviços ofertados pela medicina, mas pelo fato de as mulheres resistirem em alguns aspectos a abrir mão dessas práticas de cuidado (tradicionais) em nome dessa medicina, o que representava a autonomia para elas sobre os próprios corpos e vidas.

Percebe-se que, com a prática de partejar, as mulheres buscavam resgatar, bem como preservar, os valores culturais de suas ancestrais e fornecer ainda uma assistência humanizada às mulheres rurais, assim como o trabalho na roça (ainda que não remunerado ou não reconhecido) e a participação na religião/igreja.

As atividades de partilha de serviços e cuidados domésticos, como o parto tradicional, se definem também como um espaço de realização e prestígio das mulheres nas comunidades. Porém, tal prática segundo Barroso (2009) foi saindo de cena na medida em que o discurso higienista da classe médica irrompeu. Um "discurso modernizador e positivista tem importância na constituição de um contexto de ideias sobre o corpo da mulher" (Barroso, 2009, p. 5). Dessa forma o saber tradicional das parteiras passou a fazer parte do passado, em detrimento da legitimação e institucionalização do saber médico.

\section{Religião e religiosidade como instrumentos de apoio social na velhice}

A religião, assim como a família, é considerada uma importante instituição social, ou seja, ela exerce um papel de responsabilidade na sociedade, pelo fato de disseminar 
ideias, crenças, valores éticos e morais, o que rebate diretamente na forma de pensar e nas açôes dos indivíduos em sociedade. A religiosidade é considerada pelas idosas entrevistadas como um valor social, e em seus discursos surgiu como uma rede social de extrema importância.

No Brasil há inúmeras religiōes, porém, como narram as idosas, nas comunidades quilombolas estudadas, hoje existem duas religióes predominantes, são elas: o catolicismo e o evangelismo. As entrevistadas apontaram as práticas religiosas da igreja católica como uma tradição local, onde na fase da infância e da adolescência puderam vivenciar de maneira intensa os eventos da igreja com seus antecessores, pais e máes e principalmente com suas avós. Diz uma entrevistada:

Aqui na época, na época que eu era criança [risos] aqui tinha era uma festa de... aqui tinha uma festa de... da igreja católica de campos novos que meu pai era devoto da... de Santo Inácio, aí eles faziam aquela festa tradicional, de... de Santo Inácio, ${ }^{5}$ aí era nossa festa, missas, isso aí sempre teve, muito... Muitas igreja cristá num vai... aí aquela tradição acabou... porque entrou o evangélico aí... ficou mais fria, o católico entendeu... (Dandara dos Palmares, 2019).

Conforme apontam Mariz e Machado (1994), o catolicismo historicamente é considerado uma religião hegemônica no Brasil. As autoras afirmam que "até a década de 1960 mais de $90 \%$ da população se declarava católica" (Mariz; Machado,1994, p. 26), porém essa realidade vem se alterando ao longo dos anos, de acordo com as pesquisas que abarcam o tema da religiosidade, inclusive este estudo, que apesar de atingir uma pequena amostra, ratifica tal mudança no âmbito religioso no que concerne à conversão. Carolina de Jesus, sobre isso, diz: "[...] minha filha muito. Muita coisa, muita coisa. Converter, converteram muitas mesmo, sabe..."

Machado (2005) aponta essa mudança através dos números divulgados pelo Instituto Brasileiro de Geografia e Estatística (IBGE), que diz:

[...] enquanto a representação dos católicos na população brasileira caiu de 83,3\% para $73,8 \%$, a porcentagem dos evangélicos pulou de $9,0 \%$ para $15,4 \%$ entre 1991 e 2000. Já os sem religiáo subiram de $4,8 \%$ para $7,3 \%$ nesse mesmo período. (Machado, 2005, p. 387).

A questăo que chamou bastante atenção no discurso das idosas e, portanto, merece destaque de fato, foi a questão da conversão religiosa apontada acima, o que

5 "A igreja estabelecida no local foi consagrada a Santo Inácio, militar espanhol canonizado em 1622 e fundador da Companhia de Jesus. Esta possuía um altar central e nele estava colocada a imagem do dileto fundador, cuja lenda reza guardou a carta deixada pelos jesuítas doando a fazenda aos moradores locais” (Engemann; Amantino, 2010). 
a literatura especializada convencionou denominar de trânsito religioso. Tal conceito se caracteriza quando há uma transição de uma religiáo para outra, com denominação diversa. Nesse caso, houve na comunidade, segundo as entrevistadas, um trânsito do Catolicismo Romano para o Protestantismo. Esse fato, conforme aponta Coelho (2009), tem ocorrido de forma progressiva, e consequentemente tem reconfigurado o cenário religioso do país.

As idosas se referiram à conversão religiosa como parte do apoio necessário para a superação das dificuldades encontradas no cotidiano. Mariz e Machado (1994. p. 32) apontam que o trânsito religioso ocorre principalmente na situação exposta pelas idosas. As autoras dizem: "busca-se uma nova denominação quando os problemas persistem ou não são resolvidos satisfatoriamente". É como se a religião antiga (católica), neste caso, falhasse, na hora de solucionar as situaçōes adversas surgidas no dia a dia, e então se torna necessário buscar uma nova religiáo, a fim de fortalecer a fé, e consequentemente encontrar soluçáo para um determinado problema.

Dentre as idosas, declararam-se convertidas: Aqualtune, Tia Ciata, Carolina de Jesus e Luiza Mahin. Tereza de Benguela não declarou se houve conversão, tampouco Marielle Franco. Todas as entrevistadas declararam-se evangélicas, exceto Dandara, que afirmou não ter religião, porém frequentava a igreja quando criança. Três das idosas afirmaram que são membros da Igreja Evangélica Assembleia de Deus, são elas: Aqualtune, Luíza Mahin e Carolina de Jesus.

As idosas quando indagadas sobre a existência de cultos relacionados às religióes de matriz africana, transmitiram um gesto de negação, isto é, uma recusa em abordar tal assunto. Cinco delas afirmaram de prontidão que não sabiam da existência de tais religiôes na comunidade. Marielle Franco diz: "Dizer que.... dizer que tinha... eu também via falar... mas nunca... fui nessas coisas não". Já Tia Ciata falou sobre, porém de forma pejorativa. Ela diz:

Não... aqui... eu nunca tive... eu sou cristá, agora sou, sou cristá, mas naquela época tinha muitos nego que gostava de bater as pembazinha deles sabe, mas eu nem ia, eu nem ia... é.... Ah, tinha minha filha, ah tinha... pra li tinha uma vizinha ali que ela chegava ter o pé assim, de tâo macumbeira que ela era, mas já foi, graças à Deus já morreu... é.... então. (Tia Ciata, 2019).

Diante dos relatos elencados acima, percebe-se que há uma negação das idosas em reconhecer a origem de suas ancestrais, origem esta na qual a religiáo tem grande influência, pois constitui a identidade do povo negro. Além de abordarem suas trajetórias religiosas, as idosas enfatizaram sua participação na igreja, bem como as funçôes exercidas na instituição.

Para as idosas, a religiosidade traz enormes benefícios, pois na igreja elas trocam experiências, isto é, exercem uma participaçáo social que em determinados momentos da vida não foi possível realizar, devido principalmente à dedicação delas ao lar. 
Portanto, nessa fase da vida, em que experimentam a velhice, novos projetos de vida são postos em prática.

A religiosidade contribui ainda com a promoçáo da saúde da pessoa idosa, na medida em que garante a integraçáo social e psicológica, garantindo-lhes bem-estar, como aponta Tia Ciata ao se referir ao espaço da igreja. Ela diz: "ali a gente bota as mágoa pra fora [gargalhada]". A idosa se refere à igreja como um espaço de acolhimento, onde há relações intergeracionais e de solidariedade entre "as irmãs", bem como criação de novos laços de amizade e encontros grupais de oração.

As entrevistadas trouxeram em suas narrativas suas funçóes exercidas na igreja. Nesse momento foi perceptível a satisfação delas em ocuparem cargos que historicamente mulheres

negras, na condiçấo de classe a que pertencem, nunca ocuparam. Assim, as funçôes exercidas por elas são posiçôes como: diretora, presidente, tesoureira, diaconisa, etc. Algumas destas são consideradas, na sociedade em geral, posiçóes que denotam prestígio social, ou seja, posiçóes de status.

Para as idosas, ocupar apenas o espaço doméstico não lhes possibilita obter prestígio social, mas na igreja, torna-se possível. Acerca dessa colocação, Angela Davis, ao analisar o trabalho doméstico nas sociedades capitalistas avançadas, diz: "o trabalho doméstico, orientado pela ideia de servir e realizado pelas donas de casa, que raramente produzem algo tangível com seu trabalho, diminui o prestígio social das mulheres em geral" (Davis, 2016, p. 228).

As religiōes ditas tradicionais ainda têm muito em que avançar, pois algumas ainda permanecem estruturadas nos moldes reforçados pelo sistema patriarcal, que priorizam os homens a ocupar postos hierárquicos para desempenharem as funçóes superiores no interior das igrejas. Porém, e apesar disso, há de se considerar que houve nos últimos anos avanços consideráveis, que destacam a questão de gênero, principalmente através dos movimentos sociais, dentre eles o feminista, ${ }^{6}$ que possibilitou a ampliação da representação das mulheres nas igrejas. Um exemplo são os números crescentes do sacerdócio feminino apontado por Machado (2005), que rebate diretamente na participação política das mulheres na sociedade.

\section{Considerações finais}

Este estudo buscou apresentar as trajetórias de vida de mulheres idosas. $\mathrm{Na}$ análise, destaca-se o papel de importância exercido por estas mulheres nos Quilombos Botafogo e Caveira, no que concerne às práticas de cuidado, de trabalho, bem como

6 Para um aprofundamento maior sobre o feminismo protestante, ver: Marianno (2018). 
nas relaçóes de solidariedade e reciprocidade e na vida religiosa.

A partir dessas atividades práticas exercidas pelas mulheres, percebemos que a comunidade se beneficia como um todo, na medida em que tem suas necessidades, ainda que básicas, atendidas. Assim, se faz necessário apontar e dar visibilidade à atuação dessas mulheres, destacando seu o protagonismo, uma vez que na sociedade capitalista o trabalho reprodutivo realizado por mulheres é invisibilizado, ou seja, há uma visão reducionista neste modo de produção vigente de que o trabalho reprodutivo não gera valor.

A opressão feminina é sentida pelas mulheres quilombolas por quatro fatores principais: pela questão de gênero, raça, classe e geraçáo. Se analisarmos esses marcadores sociais, vemos que eles amplificam a condiçáo desigual da mulher na sociedade, e assim as deixam numa condição ainda mais vulnerável em relação aos homens, o que as impede de alcançar um patamar de cidadania, que engloba o direito ao trabalho digno, à educação, à liberdade, dentre outros.

Nessa perspectiva, esta pesquisa contribui de modo significativo com a produção no campo acadêmico, pois na análise acerca do envelhecimento brasileiro há uma escassa produção que trata o tema sob a perspectiva de raça. Ao pesquisar sobre o envelhecimento da população negra, percebi que há poucos estudos que analisam essa experiência. Portanto, esta pesquisa contribui de certa forma com essa discussão ainda incipiente nas pesquisas e expõe a necessidade de avançarmos nesse debate com novos estudos.

Rabelo et al. (2018, p. 195), ao analisar o racismo como fator preponderante para a experiência do envelhecimento da populaçáo negra, afirma:

[...] o racismo, com suas múltiplas determinaçóes, impacta diretamente no processo de envelhecimento da população negra, sendo imprescindível ater-se aos elementos que resultam deste. Para entender como envelhecem [os sujeitos negros], é fundamental conhecer seus indicadores socioeconômicos e de saúde ao longo da vida. E quando se tornam velhos, quais vulnerabilidades e fatores de proteção moldam a experiência do envelhecimento negro?

Esta pesquisa evidenciou também a constituição da identidade das mulheres quilombolas, através de suas memórias. As pessoas mais velhas de ambas as comunidades, consideradas como guardiâs da memória, contribuíram muito para que acessássemos a história local em sua forma mais real, mais fidedigna, por ser uma história contada por quem realmente vivenciou as experiências.

À guisa de conclusão, constatei neste estudo que, enquanto profissionais comprometidos com a classe trabalhadora e com os direitos humanos, faz-se urgente avançar no debate sobre a perspectiva interseccional cunhada por Kimberlé Williams Crenshaw. Um país que concentra mais de $50 \%$ da população negra e tem uma populaçáo acima de 60 anos com índices de crescimentos significativos precisa 
entrelaçar as variáveis aqui trazidas, que são: gênero, geração, raça e classe. Será que paramos para refletir que uma grande proporção de mulheres negras sequer chegam aos 60 anos devido aos determinantes sociais, do qual o racismo é parte, assim como o patriarcado e a desigualdade de classe?

No Serviço Social, esse entrelaçamento que venho destacando ainda é incipiente. Corroboro com a afirmação de Alves (2018, p. 280) que "o cruzamento entre raça e gênero, tal qual formulado pela abordagem interseccional, ainda é periférico na produção do Serviço Social”. A escassez na produção sobre o debate étnico-racial no Serviço Social traz limites à atuação profissional, pois trata a população como se fossemos, de fato, "todos iguais perante a lei", bem como desconsidera o racismo como marca histórica da sociedade.

Por fim, é válido salientar que conhecer as trajetórias de vida por meio da memória permitiu recuperar as histórias do passado das idosas, bem como de suas ancestrais, histórias essas que são apagadas e silenciadas. Com isso, podemos mostrar quem são, de onde vieram e seus papéis desempenhados na comunidade, que são de suma importância para garantir o bem-estar da coletividade. Essas mulheres também foram fundamentais para a economia rural e merecem tal reconhecimento. São protagonistas de sua própria história, sim. Como diz Tereza de Benguela: "a gente preto, a gente tem que ser mais reconhecido”.

\section{Referências}

ALVES, Andrea Moraes. Pensar o gênero: diálogos com o Serviço Social. Serviço Social \& Sociedade, São Paulo, n. 132, p. 268-286, ago. 2018.

BARROS, Janaína Carvalho; LINS DE BARROS, Myriam Moraes. Memórias de velhos: rememorando a trajetória de vida e a sociabilidade nas relaçóes familiares. Kairós Gerontologia, São Paulo, v. 17, n. 4, p. 337-358, dez. 2014.

BARROSO, Iraci de Carvalho. Os saberes de parteiras tradicionais e o ofício de partejar em domicílio nas áreas rurais. PRACS., Macapá, v. 2, n. 2, dez. 2009.

BOBBIO, Norberto. O tempo da memória. Rio de Janeiro: Campus, 1997.

BOSI, Ecléa. Memória e sociedade: lembranças de velhos. 3. ed. São Paulo: Companhia das Letras, 1994.

BRANDÃO, Vera Maria Antonieta Tordino; MERCADANTE, Elizabeth Frohlich. Envelhecimento ou Longevidade? São Paulo: Paulus, 2009. (Coleção Questôes Fundamentais do Ser Humano, 8).

CIAMPA, Antônio da Costa. A identidade social como metamorfose humana em busca da emancipação: articulando pensamento histórico e pensamento utópico. In: CONGRESSO INTERAMERICANO DE PSICOLOGIA, 29., 2003, Lima. Anais.... Lima: SIP, 3003. 
COELHO, Lázara. Divina. Trânsito religioso: uma revisão exploratória do fenômeno brasileiro. Vox Faifae, v. 1, n.1, 2009.

DAVIS, Angela. Mulheres, raça e classe. Tradução Heci Regina Candiani. São Paulo: Boitempo, 2016.

DEBERT, Guita Grin. A reinvenção da velhice: socialização e processos de reprivatização do envelhecimento. São Paulo: Fapesp, 1999.

ENGEMANN, Carlos; AMANTINO, Marcia. A fazenda de Campos Novos e sua história séculos XVII e XVIII. In: ENCONTRO REGIONAL DA ANPUH-RIO, 14., 2010, Rio de Janeiro. Anais... Rio de Janeiro: Numem, 2010.

FONSECA, Cláudia. Concepçóes de família e práticas de intervenção: uma contribuição antropológica. Saúde e Sociedade, São Paulo, v. 14, n. 2, p. 50-59, ago. 2005.

HALBWACHS, Maurice. A memória coletiva. São Paulo: Vértice, 1990.

HALBWACHS, Maurice. Los marcos sociales de la memoria. Madrid: Anthropos, 2004.

LIMA, Márcia. O uso da entrevista na pesquisa empírica. In: ABDAL, Alexandre et al. (Org.). Métodos de pesquisas em Ciências Sociais: Bloco Qualitativo. Sáo Paulo: Sesc-SP: Cebrap, 2016. p. $24-41$.

LINS DE BARROS, Myriam Moraes. Autoridade e afeto: avós, filhos e netos na família brasileira. Rio de Janeiro: Jorge Zahar, 1987.

LINS DE BARROS, Myriam Moraes. Memória e Família. Estudos Históricos, Rio de Janeiro, v. 2, n. 3, p. 29-42, 1989.

LUSA, Mailiz Garibotti. Relaçôes de gênero no campo: a superação dos papéis tradicionais como desafio à proteçáo social básica e o papel dos assistentes sociais. Gênero, Niterói, v. 13, n. 1, p. 93-107, 2012.

MACHADO, Maria das Dores Campos. Representaçôes e relaçóes de gênero nos grupos pentecostais. Estudos Feministas, Florianópolis, v. 13, n. 2, p. 387-396, ago. 2005.

MARIANNO, Lília Dias. Feminismo protestante. In: HOLLANDA, Heloisa Buarque de (Org.). Explosão feminista. São Paulo: Companhia das Letras, 2018.

MARIZ, Cecília; MACHADO, Maria das Dores Campos. Sincretismo e trânsito religioso: comparando carismáticos e pentecostais. Comunicaçóes do ISER, Rio de Janeiro, n. 45, ano 13, 1994.

PERROT, Michelle. Minhas histórias das mulheres. São Paulo: Contexto, 2007.

POLLAK, Michael. Memória, esquecimento, silêncio. Estudos Históricos. Rio de Janeiro, v. 2, n. 3, p. $3-15,1989$.

RABELO, Dóris Firmino; SILVA, Josevânia da; ROCHA, Nara Maria Forte Diogo; GOMES, Hiago Veras; ARAÚJO, Ludgleydson Fernandes de. Racismo e envelhecimento da população negra. Kairós Gerontologia, São Paulo, v. 21, n. 3, p. 193-215, 2018.

ROCHA, Tânia Maria Rodrigues da. Memória, trabalho e envelhecimento de mulheres negras idosas em uma comunidade remanescente de Quilombo São Joaquim de Paulo em Vitória da Conquista 
- Bahia. Dissertação (Mestrado em Memória Linguagem e Sociedade) - UESB, Vitória da Conquista, BA, 2015.

SANTOS, Myrian Sepúlveda. Memória coletiva e teoria social. 2. ed. São Paulo: Annablume, 2012.

TODOROV, Tzvetan. Em face do extremo. Campinas: Papirus, 1995. (Coleção Travessia do Século).

\section{Fontes orais}

DUTRA, Maria dos Santos (Aqualtune) [85 anos]. [ago. 2019]. Entrevistadora: Dayara da Silva Ferreira. Arraial do Cabo, RJ, 3 ago. 2019.

GABRI, Maria Inês dos Santos (Carolina de Jesus) [62 anos]. [out. 2019]. Entrevistadora: Dayara da Silva Ferreira. Arraial do Cabo, RJ, 21 out. 2019.

LIMA, Maria da Conceição Silveira (Dandara dos Palmares) [62 anos]. [jul. 2019]. Entrevistadora: Dayara da Silva Ferreira. Arraial do Cabo, RJ, 22 jul. 2019.

MONTEIRO, Nanci Geralda Silveira Monteiro (Tereza de Benguela) [64 anos]. [out. 2019]. Entrevistadora: Dayara da Silva Ferreira. Arraial do Cabo, RJ, 18 out. 2019.

SANTOS, Almerinda Eulália Conceição (Luíza Mahin) [77 anos]. [set. 2019]. Entrevistadora: Dayara da Silva Ferreira. Arraial do Cabo, RJ, 18 set. 2019.

SILVA, Maria Antonina (Tia Ciata) [80 anos]. [out. 2019]. Entrevistadora: Dayara da Silva Ferreira. Arraial do Cabo, RJ, 30 out. 2019.

SOUZA, Dionice da Silva (Marielle Franco) [70 anos]. [set. 2019]. Entrevistadora: Dayara da Silva Ferreira. Arraial do Cabo, RJ, 18 set. 2019.

Recebido em 02/03/2021.

Versão final reapresentada em 30/04/2021.

Aprovado em 04/05/2021.

Certificado de Apresentaçáo de Apreciaçáo Ética (CAAE): 15203519.4.0000.5582.

Fonte de financiamento: Coordenação de Aperfeiçoamento de Pessoal de Nível Superior (Capes) - Auxílio à pesquisa.

Conflitos de interesse: nada a declarar. 